\title{
Silver and gold nanoparticles from tannic acid: synthesis, characterization and evaluation of antileishmanial and cytotoxic activities
}

\author{
LOURDES C.S. LOPES ${ }^{1}$, LUCAS M. BRITO ${ }^{2}$, THAYLLAN T. BEZERRA ${ }^{1}$, KLEYTON N. GOMES ${ }^{1}$, \\ FERNANDO A. DE A. CARVALHO ${ }^{2,3}$, MARIANA HELENA CHAVES ${ }^{1}$ and WELTER CANTANHÊDE ${ }^{1}$ \\ ${ }^{1}$ Departamento de Química, Universidade Federal do Piauí, Campus Universitário \\ Ministro Petrônio Portella, Bairro Ininga, 64049-550 Teresina, PI, Brazil \\ ${ }^{2}$ Núcleo de Pesquisas em Plantas Medicinais, Universidade Federal do Piauí, Campus Universitário \\ Ministro Petrônio Portella, Bairro Ininga, 64049-550 Teresina, PI, Brazil \\ ${ }^{3}$ Departamento de Bioquímica e Farmacologia, Universidade Federal do Piauí, Campus \\ Universitário Ministro Petrônio Portella, Bairro Ininga, 64049-550 Teresina, PI, Brazil \\ Manuscript received on August 4, 2017; accepted for publication on October 30, 2017
}

\begin{abstract}
Gold $\left(\mathrm{Au}^{0}\right)$ and silver $\left(\mathrm{Ag}^{0}\right)$ nanoparticles were synthesized using tannic acid (TA) as both reducing and stabilizer. Nanoparticles formation, stability, and interaction with TA were compared to citrate-coated nanoparticles and monitored by UV-Vis, zeta potential, and transmission electron microscopy. TA coating resulted in a red-shift and broadening of bands compared to citrate-coated nanoparticles (NPs-Cit). AgNPsTA and AuNPs-TA are negatively charged with mean surface charge of $-29.4 \mathrm{mV}$ and $-29.6 \mathrm{mV}$, respectively. TEM images showed polydispersety of AuNPs-TA (6-42 nm) and aggregation of AgNPs-TA (12-71 nm). In vitro assays of Leishmania amazonensis promastigotes showed an increment of antileishmanial activity for AgNPs-TA in relation to AgNPs-Cit, while AuNPs-TA and AuNPs-Cit did not affect the protozoas at tested concentrations. $\mathrm{CC}_{50}$ value for AgNPs-TA suggested that TA attenuates nanosilver toxicity comparatively to its precursor $\left(\mathrm{Ag}^{+}\right)$. This investigation can contribute to the development of new, green, and fast produced drugs aiming at leishmaniasis treatment.
\end{abstract}

Key words: green synthesis, leishmaniasis, metallic nanoparticles, tannic acid.

\section{INTRODUCTION}

Leishmaniases are a group of infectious and non-contagious severe parasitic diseases, caused by protozoans of the Leishmania genus. The transmission occurs through blood meal of infected female sand flies of the genera Phlebotomus, that are considered as intermediate hosts of these

Correspondence to: Welter Cantanhêde

E-mail:welter@ufpi.edu.br parasites. The flagellate promastigote form of the parasite is present in the sand fly, and once engulfed by host macrophages, it converts into the aflagellate amastigote form (Kevric et al. 2015, Carneiro et al. 2012). This disease is endemic in near 100 countries worldwide and affects 12 million people residing in tropical and subtropical areas. Annually, about 2 million new cases emerge worldwide, wherein 1.5 million are cutaneous leishmaniasis and 500,000 are visceral leishmaniasis, the most severe form 
of the disease (Oryan and Akbari 2016, No 2016, Krevic et al. 2015, Carneiro et al. 2012, Jebali and Kazemi 2013).

The treatment of leishmaniasis is still mainly based on the administration of pentavalent antimonials, old and expensive drugs, with high toxicity to heart, kidneys, and liver, clinically used since the beginning of the last century. Some parasites developed resistance to these drugs, thus, there is a need to identify novel antileishmanial agents for an effective and non-toxic therapy (Oryan and Akbari 2016, No 2016, Blanco and Nascimento-Júnior 2017).

Nanoparticles (NPs) play an important role in the diagnosis and treatment of diseases in consequence of their larger surface areas in comparison to the bulk material. (Qasim et al. 2014, Akbari et al. 2017). Nanoparticles properties are intrinsic to size, distribution, and morphology which can improve their optical, electronic, magnetic and catalytic features (Melo et al. 2012, Paino et al. 2012, Sharma et al. 2009, Silva et al. 2013, Bhosale et al. 2014). Among the variety of nanomaterials, noble metal nanoparticles (NMNPs) present unique physical, chemical and biological properties. NMNPs are used in chemical and biochemical sensors, medical diagnoses and therapeutics, biological imaging, catalysis, microelectronic, photovoltaic cells and bactericides (Medici et al. 2015, Hatipoglu et al. 2015, El-Bashir et al. 2013, Paramasivam et al. 2017).

Especially for medical science applications, NMNPs are suitable to treat severe or chronic diseases. Countless studies demonstrate that silver nanoparticles, silver ions, and nanosilver-containing complexes have antimicrobial behavior with high ability to inactivate bacteria and viruses (Catalano et al. 2016, Jebali and Kazemi 2013, Sharma et al. 2009, Chen et al. 2011). Similarly, some reports indicate the efficacy of gold nanoparticles in diagnosis and treatment of certain cancers, as well as antibacterial properties (Lazarus and Singh et al. 2016).
Despite the extensive reports of antibacterial, antiviral and antifungal activities of metallic nanoparticles, researches focused on antileishmanial activity of these nanomaterials are still limited. Mohebali et al. (2009) demonstrated the efficacy of silver nanoparticles on L. major, with these being shown to be promising for treatment of cutaneous leishmaniasis. The same effect was observed by Torabi et al. (2011) with gold nanoparticles on $L$. major. Allahverdiyev et al. (2011) evaluated the antileishmania effect of silver nanoparticles on $L$. tropica based on investigation of their action on various cellular parameters of the promastigote and amastigote forms of parasite when in the absence and presence of UV light.

Allied to this, researchers have been focusing on "environmental friendly approaches" to produce biocompatible metallic nanoparticles from natural materials. For instance, Iravani and Zolfaghari (2013) prepared silver nanoparticles using Pinus eldarica bark extract and optimized the biosynthesis process. In another study, Dubey et al. (2010) synthesized gold and silver nanoparticles with spherical and triangular shapes, using Tanacetum vulgare (tansy) fruits extract. Finally, Sheny et al. (2012) produced hexagonal gold nanoparticles with an essential oil from leaves of Anacardium occidentale. In addition to plants, organisms such as fungi and bacteria have been also used to produce nanoparticles, but plants tend to reduce metal ions faster.

In this perspective, gold and silver nanoparticles were synthesized with a polyphenolic compound resulting in a hybrid nanomaterial. We used tannic acid (TA), a typical hydrolysable tannin derived from plants with diverse biological properties such as antioxidant, antitumoral, antimutagenic, antimicrobial and anti-inflammatory actions, in addition to its capability of interaction with proteins. Tannin structure contains digalloyl ester groups connected to a glucose central core (Fig. 1) which allow interactions based on ionic pairing, 
hydrogen bonding, and metal coordination. (Yi et al. 2011, Liu et al. 2014, Abed et al. 2013, Chung and Reed 2012, Kumari et al. 2013, Zhang et al. 2015, Tikoo et al. 2011).

There are reports that tannic acid has significant effect on dispersion and mobility of nanomaterials in aqueous medium (Zhang et al. 2015, Espinasse et al. 2007). In nanoparticles formation, TA acts simultaneously as reducing agent and stabilizer due to the amount of hydroxyl groups and its dendritic macrostructure (Yi et al. 2011, Bulut and Ozacar 2009, Iravani 2011). Nanoparticles stabilization may be influenced by factors shown by Brunel et al. (2009). such as time, ionic strength, temperature, and $\mathrm{pH}$.

Incorporation of natural products to synthesize hybrid nanomaterials promotes low environmental toxicity and less synthesis-associated biological hazards. Also, this practice contributes to developing stable and biocompatible nanomaterials, enhancing their value for medicine (Medici et al. 2015, Agnihotri et al. 2013, Silva et al. 2013). In this work, TA was used as reducing and capping agent to synthesize silver and gold nanoparticles aiming at a more effective treatment for leishmaniasis. We investigated the formation, morphology, shape, size, surface charge, and antileishmanial activity, using

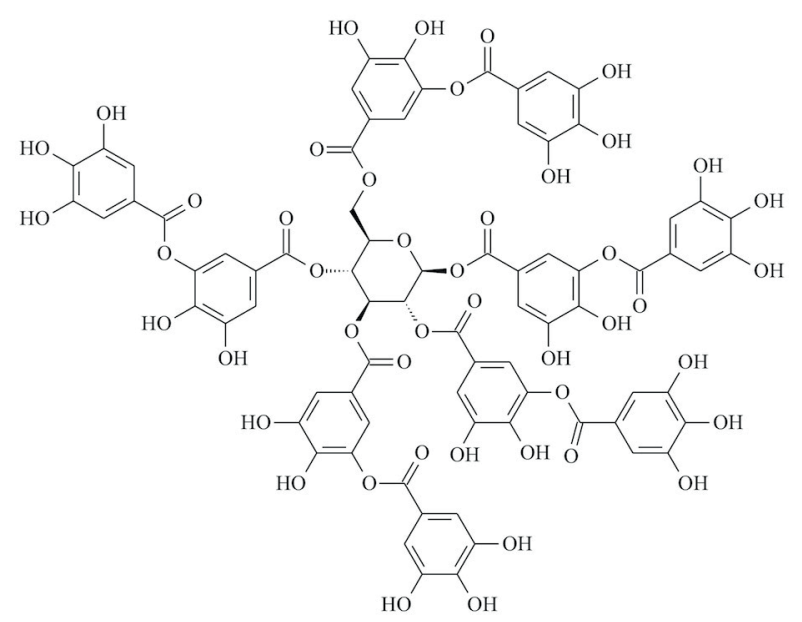

Figure 1 - Chemical structure of TA compound. electronic microscopy and spectroscopic techniques, zeta potential data, and pharmacological assays.

\section{MATERIALS AND METHODS}

\section{CHEMICALS AND MATERIALS}

All chemicals were analytical grade and used as received. Silver nitrate $\left(\mathrm{AgNO}_{3}, 99.0 \%\right)$ and tetrachloroauric acid trihydrate $\left(\mathrm{HAuCl}_{4} \cdot 3 \mathrm{H}_{2} \mathrm{O}\right.$, 99.9\%) were purchased from Sigma-Aldrich, while tannic acid (TA) $\left(\mathrm{C}_{76} \mathrm{H}_{52} \mathrm{O}_{46}\right)$ and trisodium citrate dihydrate $\left(\mathrm{Na}_{3} \mathrm{C}_{6} \mathrm{H}_{5} \mathrm{O}_{7} \cdot 2 \mathrm{H}_{2} \mathrm{O}\right)$ were acquired from Synth and Merck, respectively. All solutions were prepared using ultrapure water supplied by a Purelab Option-Q (Elga) system, with resistivity of $18.2 \mathrm{M} \Omega \cdot \mathrm{cm}$.

\section{ANIMALS}

Female BALB/c mice were used to evaluate cytotoxic activity by obtaining peritoneum macrophages. All procedures were approved by the Ethics Committee of the Federal University of Piauí, Process Number 048/2015.

\section{PARASITES}

Antileishmania assays were performed at the Laboratory of Antileishmania Activity, located at the Nucleus for Research on Medicinal Plants (Federal University of Piauí). Leishmania amazonensis strains (IFLA/BR/67/PH8) were kept into Schneider's medium supplemented with $10 \%$ inactivated fetal calf serum (FCS), penicillin (100 $\left.\mathrm{U} \cdot \mathrm{mL}^{-1}\right)$ and streptomycin $\left(100 \mathrm{mg} \cdot \mathrm{mL}^{-1}\right)$ at $26^{\circ} \mathrm{C}$, all of them from Sigma-Aldrich.

\section{PREPARATION OF AuNPs-TA AND AuNPs-Cit}

In a reaction flask, $4 \mathrm{~mL}$ of $1.96 \times 10^{-4} \mathrm{~mol} \cdot \mathrm{L}^{-1} \mathrm{TA}$ $\left(7.84 \times 10^{-7} \mathrm{~mol}\right)$ were added to $6 \mathrm{~mL}$ of $1.3 \times 10^{-3}$ $\mathrm{mol} \cdot \mathrm{L}^{-1} \mathrm{HAuCl}_{4} \cdot 3 \mathrm{H}_{2} \mathrm{O}\left(7.8 \times 10^{-6} \mathrm{~mol}\right)$ at $25^{\circ} \mathrm{C}$. The mixture was kept under vigorous magnetic stirring for $3 \mathrm{~h}$, when the colloidal dispersion immediately changed from yellow to violet, indicating AuNPs- 
TA formation. Citrate-coated gold nanoparticles (AuNPs-Cit) were obtained by Paino et al. (2012) method and used as experimental control. $1 \mathrm{~mL}$ of $1 \%(\mathrm{w} / \mathrm{v})$ citrate was added to $14 \mathrm{~mL}$ of boiling 0.5 $\mathrm{mmol} \cdot \mathrm{L}^{-1} \mathrm{HAuCl}_{4} \cdot 3 \mathrm{H}_{2} \mathrm{O}$, under vigorous stirring. The dispersion was kept under heating for additional 10 minutes, and stirred for $15 \mathrm{~min}$. AuNPs-TA and AuNPs-Cit were stored and protected from light for further use.

\section{PREPARATION OF AuNPs-TA AND AuNPs-Cit}

In a reaction flask, $5 \mathrm{~mL}$ of $1.96 \times 10^{-4} \mathrm{~mol} \cdot \mathrm{L}^{-1}$ TA $\left(9.8 \times 10^{-7} \mathrm{~mol}\right)$ were added on $5 \mathrm{~mL}$ of 4.04 x $10^{-3} \mathrm{~mol} \cdot \mathrm{L}^{-1} \mathrm{AgNO}_{3}\left(2.02 \times 10^{-5} \mathrm{~mol}\right)$ at $25{ }^{\circ} \mathrm{C}$. The mixture was kept under vigorous magnetic stirring for $5 \mathrm{~h}$, until a brown colloidal dispersion of AgNPs-TA was observed. Citrate-coated silver nanoparticles (AgNPs-Cit) were prepared as comparative effect using the chemical reduction method proposed by Cañamares et al. (2005). $1 \mathrm{~mL}$ of a $1 \%(\mathrm{w} / \mathrm{v})$ trisodium citrate aqueous solution was added to $50 \mathrm{~mL}$ of a boiling $10^{-3}$ $\mathrm{mol} \cdot \mathrm{L}^{-1} \mathrm{AgNO}_{3}$ solution and kept in this condition during $1 \mathrm{~h}$, resulting in a turbid gray dispersion. Finally, AgNPs-TA and AgNPs-Cit were stored and protected from light for further use.

\section{CHARACTERIZATIONS}

UV-Vis spectra were recorded in absorbance mode (range 200-900 nm) with a double beam Allcrom UV-6100S spectrophotometer to track the formation of nanoparticles. Shape, morphology and particle size distribution were evaluated by Transmission Electron Microscopy (TEM, JEOL JEM 2011, $200 \mathrm{kV}$ ). A drop of each dispersion (AuNPs-TA or AgNPs-TA) was cast on the copper grid and allowed to dry at room temperature. Images were digitally obtained by the Gatan digital micrograph software package. The Malvern Zetasizer Nano-ZS (Malvern Instruments Ltd.) was used to measure the zeta potential values from metallic nanoparticles coated by tannic acid, which infer about their surface charge and stability. Measurements for zeta potential were performed in triplicate, using $1 \mathrm{~mL}$ of each suspension at room temperature $\left(25^{\circ} \mathrm{C}\right)$.

EVALUATION OF THE HYBRID NANOMATERIALS AGAINST Leishmania amazonensis PROMASTIGOTES

L. amazonensis promastigotes at logarithmic growing phase were placed in 96-well microplates $\left(1 \times 10^{6}\right.$ Leishmania/well) wherein eight concentrations of substances (from 167 to $1.30 \mu \mathrm{g} \cdot \mathrm{mL}^{-1}$ for TA, from 77.49 to $0.61 \mu \mathrm{g} \cdot \mathrm{mL}^{-1}$ for AuNPs-TA and from 110 to $0.86 \mu \mathrm{g} \cdot \mathrm{mL}^{-1}$ for AgNPs-TA) were added and incubated for $48 \mathrm{~h}$. Missing $6 \mathrm{~h}$ to end the incubation, $20 \mu \mathrm{L}$ of 1 $\mathrm{mmol} \cdot \mathrm{L}^{-1}$ resazurin were added and the microplates were incubated again.

Similarly, citrate-coated nanoparticles were added in 96-well microplates to investigate alterations in the antileishmanial activity after TA incorporation. Eight concentrations of each substance were added: from 46 to $0.36 \mu \mathrm{g} \cdot \mathrm{mL}^{-1}$ for AuNPs, from 53.5 to $0.42 \mu \mathrm{g} \cdot \mathrm{mL}^{-1}$ for AgNPs and from 6.67 to $0.05 \mu \mathrm{g} \cdot \mathrm{mL}^{-1}$ for sodium citrate.

The plates reading was performed by an absorbance Biotek ELx800 plate reader, operating at $550 \mathrm{~nm}$. Assays were realized in triplicate and shown in terms of growth inhibition (\%).

\section{CITOTOXICITY ASSESSMENT}

The cytotoxicity of nanomaterials, as well as their precursors, was assessed by the MTT test (3-(4,5-dimethyl-2-thiazolyl)-2,5-diphenyl-2Htetrazolium bromide). Macrophages were elicited from BALB/c mice. In a 96-well plate, it was added $100 \mu \mathrm{L}$ RPMI 1640 supplemented and about $2 \times 10^{5}$ macrophages/well. Cells were incubated at $37{ }^{\circ} \mathrm{C}$ and $5 \% \mathrm{CO}_{2}$, for $4 \mathrm{~h}$ and then, washed twice with RPMI 1640 supplemented medium, followed by addition of $100 \mu \mathrm{L}$ of medium and TA, sodium citrate, $\mathrm{AgNO}_{3}, \mathrm{AgNPs}^{-\mathrm{TA}}$ and AgNPs-Cit in concentrations ranging from 167 to $1.30 \mu \mathrm{g} \cdot \mathrm{mL}^{-1}$, $5 \times 10^{3}$ to $39.06 \mu \mathrm{g} \cdot \mathrm{mL}^{-1} ; 220$ to $1.72 \mu \mathrm{g} \cdot \mathrm{mL}^{-1}$; 110 to $0.86 \mu \mathrm{g} \cdot \mathrm{mL}^{-1}$ and 53.43 to $0.42 \mu \mathrm{g} \cdot \mathrm{mL}^{-1}$, 
respectively. The plate was incubated for $48 \mathrm{~h}$. Then, contents were discarded and $90 \mu \mathrm{L}$ of RPMI medium supplemented with $10 \mu \mathrm{L}$ of MTT diluted in PBS (Phosphate Buffer Saline, $5 \mathrm{mg} \cdot \mathrm{mL}^{-1}$ ) were added. The plate was again incubated at $37{ }^{\circ} \mathrm{C}$ and $5 \% \mathrm{CO}_{2}$ for $4 \mathrm{~h}$, when the supernatant was discarded and $100 \mu \mathrm{L}$ of DMSO were added in wells. The plate was placed on a Kline stirrer (model AK 0506) for $30 \mathrm{~min}$ at the room temperature. Finally, reading was performed at $550 \mathrm{~nm}$ and results were expressed as mean cytotoxic concentration $\left(\mathrm{CC}_{50}\right)$, which is the toxic concentration for $50 \%$ of cells.

\section{STATISTICAL ANALYSIS}

All tests were carried out in triplicate and all results were expressed as mean \pm standard error of the mean (SEM). Data obtained for each experiment was compared by One-Way Analysis of Variance (ANOVA) followed by post hoc Bonferroni's Multiple Comparison Test, utilizing Graph Pad Prism program software version 5.0. Inhibitory and cytotoxic concentrations at $50 \%\left(\mathrm{IC}_{50}\right.$ and $\mathrm{CC}_{50}$, respectively) were calculated using probit regression analysis (IBM SPSS Statistics 20.0.0 program $)$. $P$-values $<0.05$ were considered statistically significant.

\section{RESULTS AND DISCUSSION}

It is well-known that some metallic nanoparticles show absorption bands in the visible region due to collective oscillation of electrons in resonance with incident electromagnetic radiation, called surface plasmon resonance (SPR) band (Melo et al. 2012). Thereby, AuNPs-TA and AgNPs-TA formation was first confirmed by electronic spectroscopy (Fig. 2) through their respective SPR bands at 529 and $475 \mathrm{~nm}$, since these bandas are typical of the nanosized gold and silver, respectively. Note in the spectra, for both cases, the absence of bands of the precursors' salts, suggesting the reduction of the metallic species.
Electronic spectra of precursors were compared to the TA and citrate-coated nanoparticles to evidence the reduction process (Figure S1 Supplementary Material). For TA, two bands were observed at $207 \mathrm{~nm}\left(\varepsilon=11151.4 \mathrm{~L} \cdot \mathrm{mol}^{-1} \cdot \mathrm{cm}^{-1}\right)$ and $277 \mathrm{~nm}\left(\varepsilon=973 \mathrm{~L} \cdot \mathrm{mol}^{-1} \cdot \mathrm{cm}^{-1}\right)$ attributed to electronic transitions of the aromatic rings conjugated with the carbonyl groups (Shutava et al. 2005). Two bands were observed for $\mathrm{HAuCl}_{4(\mathrm{aq})}$, both attributed to the metal-ligand charge transfer (Huang et al. 2010) at $216 \mathrm{~nm}\left(\varepsilon=3262.2 \mathrm{~L} \cdot \mathrm{mol}^{-1} \cdot \mathrm{cm}^{-1}\right)$ and a small band at $280 \mathrm{~nm}\left(\varepsilon=462.2 \mathrm{~L} \cdot \mathrm{mol}^{-}\right.$ $\left.{ }^{1} \cdot \mathrm{cm}^{-1}\right)$. The band of $\mathrm{AgNO}_{3(\mathrm{aq})}\left(\lambda_{\max }=320 \mathrm{~nm}, \varepsilon=\right.$ $\left.17.04 \mathrm{~L} \cdot \mathrm{mol}^{-1} \cdot \mathrm{cm}^{-1}\right)$ refers to the overlap of the ionic bands of $\mathrm{Ag}_{(\mathrm{aq})}^{+}$and $\mathrm{NO}_{3 \text { (aq) }}^{-}$(Yang et al. 2011). It is important to point out that sodium citrate does not show any absorbance in the UV-Vis spectrum (Mishira et al. 2013).

TA-coated gold and silver nanoparticles SPR bands were red-shifted compared to values reported in literature, 520 and 380-450 nm, respectively (Sharifi et al. 2015, Silva et al. 2013). This bathochromic effect is likely caused by the supramolecular interaction between the nanoparticles and the surface-protecting TA polyphenol, altering the electron transfer energy. Besides shape, size and type of the material, the position of the SPR band is highly dependent on the dieletric constant of the surrounding medium, once it changes the resonance frequency of the electrons onto NMNPs' surface (Song and Jing 2017, Martinsson et al. 2014, Mahmoud et al. 2012).

AuNPs-Cit and AgNPs-Cit were synthesized to understand and evaluate the effect of TA on the SPR bands and antileishmanial activity. For this purpose, sodium citrate, a weaker reducing agent, was employed in the growth solution. It is interesting to emphasize that small and spherical nanoparticles can be generated in the presence of a strong reducing agent (e.g., sodium borohydride), however, these nanoparticles are highly unstable without a stabilizing agent, tending to agglomerate, and then, precipitate. (Agnihotri et al. 2014). 
AuNPs-Cit and AgNPs-Cit exhibited SPR bands at 519 and $442 \mathrm{~nm}$, respectively, which are values consistent with those previously reported (Fig. S2) (El-Bashir et al. 2013, Silva et al. 2013). Furthermore, both TA-coated nanoparticles have broader bands than citrate-coated ones, indicating an increase in the size or aggregation of nanoparticles (Melo et al. 2012), later proved by TEM measurements. Tyndall effect, an optical phenomenon inherent to colloidal systems that consist of incident light scattering, was observed for all nanomaterials (inset of Fig. 2).

AgNPs-TA and AuNPs-TA size, shape, and polydispersity were investigated by TEM measurements. AgNPs-TA formed aggregates due to the approximation between nanoparticles with sizes from 12-71 nm, which prevented the particle size count (Fig. 3a), agreeing with the broad band behavior observed for AgNPs-TA (Bulut and Ozacar 2009, Asharani et al. 2008). The drying process for TEM sample preparation, also promotes non-homogeneous deposition, thus, nanoparticles may aggregate as the solvent evaporates (Michen et al. 2015). For AuNPs-TA, TEM images indicated the formation of polydisperse spherical particles from 6-42 $\mathrm{nm}$ each as shown in Fig. 3b. AuNPs with similar features were recently synthesized

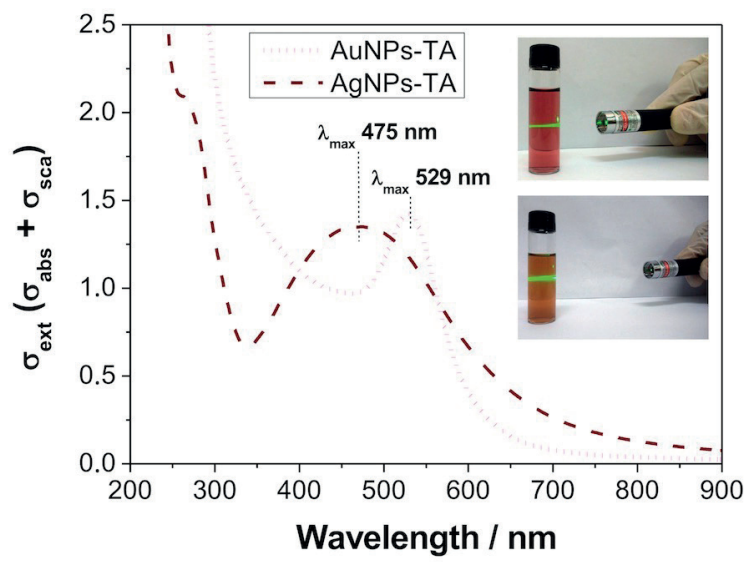

Figure 2 - UV-Vis electronic spectra for colloidal dispersions of coated nanoparticles. Inset: Tyndall effect observed for each dispersion.

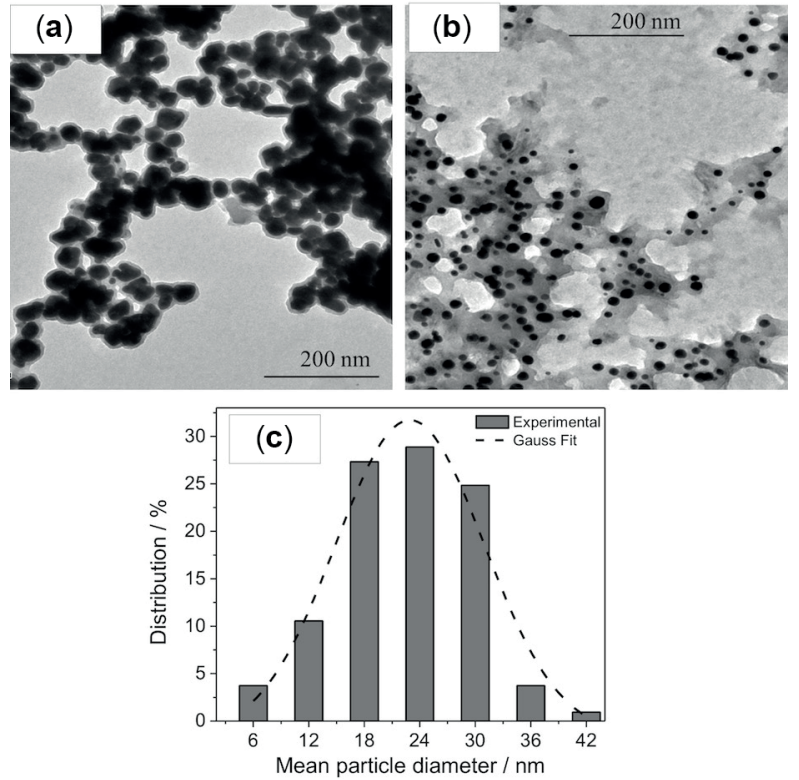

Figure 3 - TEM images for (a) AgNPs-TA, (b) AuNPs-TA and (c) size distribution histogram obtained from TEM images (322 nanoparticles) of AuNPs-TA, showing their diameters.

by Silva et al. (2013), using chitosan polymer as a stabilizing agent. The distribution and the absence of agglomerates, in both cases, prove that the organic compound avoids the nanoparticles agglomeration. Histograms of the particle size distribution of 322 nanoparticles showed an approximate mean diameter of $23.0 \pm 0.8 \mathrm{~nm}$ (Gauss fit, Fig. 3c). TA coating increases particle size compared to conventional methods, which also influences on nanoparticles growth. Recently, Santos et al. (2016) studied the influence of TA in the synthesis step of $\mathrm{Fe}_{3} \mathrm{O}_{4}$ nanoparticles with several sizes and shapes.

Zeta potential measurements were obtained to evaluate surface charges and stabilities of AgNPsTA and AuNPs-TA colloidal dispersions. Mean surface charge values for AgNPs-TA $(\zeta=-29.4$ $\mathrm{mV})$ and AuNPs-TA $(\zeta=-29.6 \mathrm{mV})$ indicated that the metallic nanoparticles surfaces were negatively charged. In general, positive or negative zeta potential values depend on some factors (Ostolska and Wisniewska 2014) as: 1) $\mathrm{pH}$ of the medium; 2) type of functional groups present in the stabilizer and 3) molecular weight of the material of interest. 
Since the $\mathrm{p} K_{\mathrm{a}}$ value ca. 10.0 of TA (Lopes et al. 1999, Herrera-Becerra et al. 2010) was higher than the $\mathrm{pH}$ value of colloidal dispersions of the hybrid materials (3.5 and 4.0 for $\mathrm{Au}$ and AgNPs coated by TA, respectively), the gallic acid units that form TA are probably partially ionized in the hydroxyl paracarbonyl position due to its steric hindrance (or molecular weight) in acidic medium. In addition, the hydroxyl meta-carbonyl position is better stabilized by resonance than its conjugate base. Therefore, in these cases, there is an unbalance of charge on AgNPs (or AuNPs) surface (containing TA) due to adsorbed polyphenolic compounds and dissociated functional groups present in their structures that probably are responsible for the negative values of the zeta potential exhibited by colloidal dispersions. Also, the high values of zeta potential exhibited by hybrid materials also explain why the tannin prevents the coalescence between nanoparticles, as evidenced by TEM technique, and their high colloidal stabilities. Furthermore, these values are consistent with those presented by Dubey et al. (2010) who used Tanacetum vulgare (tansy) fruits extract as reducing agent in the formation of significantly stable silver $(\zeta=-26 \mathrm{mV})$ and gold $(\zeta$ $=-31 \mathrm{mV}$ ) nanoparticles.

Unfortunately, the FTIR and NMR measurements for AuNPs-TA and AgNPs-TA materials were inconclusive, even after altering experimental conditions. For example, in aqueous medium and supported onto solid substrate the FTIR spectra for AgNPs-TA, AuNPs-TA and TA exhibited practically the same behavior with stretches and bands of the main functional groups (carbonyl, aromatic rings and phenolic hydroxyl) without displacement or change in the signal intensities, due to the low concentration of the $\mathrm{Ag}$ and $\mathrm{Au}$ nanoparticles when compared to TA compound. The concentration of nanomaterials also compromised in NMR experiments.

The need for new and more effective treatments in the fight against leishmaniasis comes from the high toxicity of currently applied drugs and the emergence of resistant parasites (Maquiaveli et al. 2017, Carneiro et al. 2012, Jebali and Kazemi 2013, Vieites et al. 2009, Allahverdiyev et al. 2011). In this context, in vitro antileishmanial assays were performed with L. amazonensis promastigotes. AgNPs-TA (Fig. S3) caused total inhibition at the concentration of $110 \mu \mathrm{g} \cdot \mathrm{mL}^{-1}$, while TA showed less efficacy and there was not total growth inhibition for tested concentrations.

Inhibitory effects of these substances are grouped in Fig. 4. $\mathrm{IC}_{50}$ values were determined as $221.81 \pm 97.08 \mu \mathrm{g} \cdot \mathrm{mL}^{-1}$ and $5.85 \pm 1.76 \mu \mathrm{g} \cdot \mathrm{mL}^{-1}$ for TA and AgNPs-TA, respectively (Table I), thus, confirming the increment of the antileishmanial activity for AgNPs-TA near by 40 times.

AgNPs-Cit $\left(\mathrm{IC}_{50}=6.96 \pm 3.49 \mu \mathrm{g} \cdot \mathrm{mL}^{-1}\right.$, Table I) promoted growth inhibition in the first four concentrations, similarly to AgNPs-TA (Fig. $\mathrm{S} 4)$. This agreement between the $\mathrm{IC}_{50}$ values corroborates to the efficacy of nanosilver against Leishmania amazonensis.

Based on microscopic views obtained after quick panoptic staining (Fig. 5), we found that promastigotes retained their morphologies when exposed to AuNPs-TA and AuNPs-Cit, as well as in the control group (Fig. S5), while with AgNPsTA and AgNPs-Cit, promastigotes assumed an

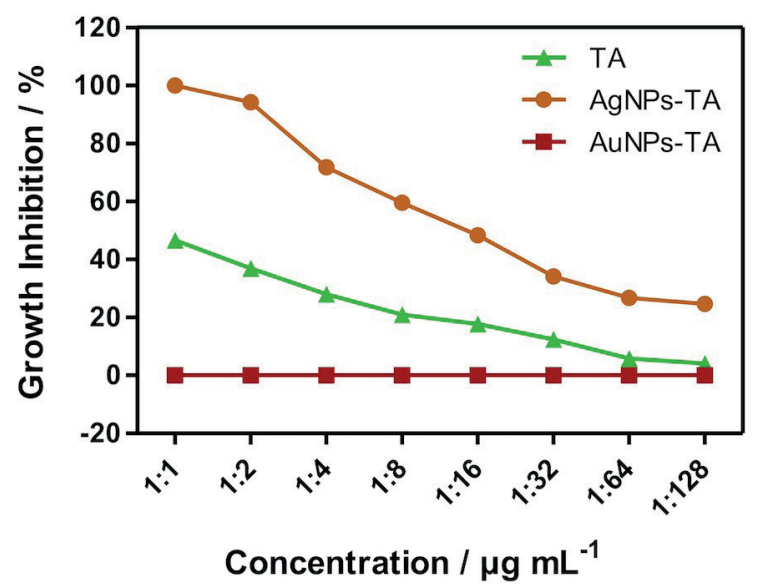

Figure 4 - Comparison of inhibitory effect between hybrid nanomaterials and TA compound. 


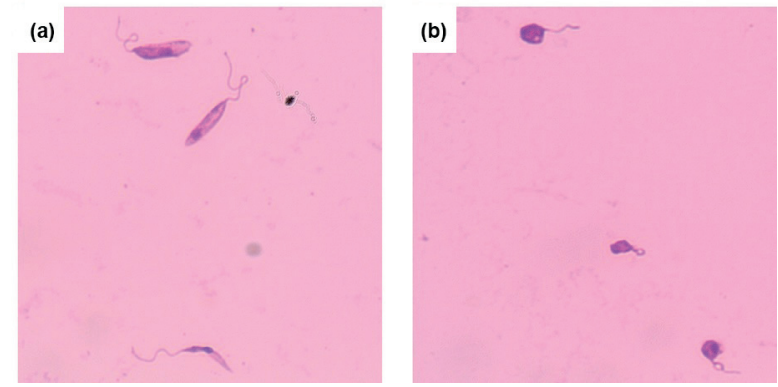

Figure 5 - Optical microscopy views of parasite cultures (a) exposed to AuNPs-TA and (b) exposed to AgNPs-TA. Quick panoptic staining and 100x magnification.

atypical appearance due to the disruption of their membranes, being impossible to distinguish their shape. Furthermore, the cells number decreased significantly comparatively to the control group.

The appearance of parasites in the presence of AgNPs-TA and AgNPs-Cit suggests some possible mechanisms of action. Previously literature, report that silver attacks bacteria's cell membrane surface, altering permeability, osmotic equilibrium and thus, metabolic pathways of the cell. Silver nanoparticles may also bind to the DNA, preventing replication (Jebali and Kazemi 2013, Chen et al. 2011, Perni et al. 2009, Allahverdiyev et al. 2011, Durán et al. 2010). Future works should be conducted to elucidate the mechanism of action of the TA-coated nanosilver on Leishmania.

AuNPs-TA and AuNPs-Cit did not show antileishmania activity at any tested concentration. This can be associated with the inert nature of the metal against aggressions of corrosive nature (Pereira et al. 2007).

Cytotoxic activity evaluation is essential in the search for specific and less toxic antileishmanial agents. In this sense, TA and citrate were noncytotoxic (Table I) while the silver salt had high cytotoxic activity, with cell death near $80 \%$ at 0.0022 $\mu \mathrm{g} \cdot \mathrm{mL}^{-1}$. AgNPs-TA $\left(\mathrm{CC}_{50}=2.38 \pm 1.44 \mu \mathrm{g} \cdot \mathrm{mL}^{-1}\right.$, Table I) and AgNPs-Cit $\left(\mathrm{CC}_{50}=17.10 \pm 4.32\right.$ $\mu \mathrm{g} \cdot \mathrm{mL}^{-1}$, Table I and Fig. S6) had high cytotoxicity (Fig. 6), which demonstrated that tannin and citrate coating attenuate the toxicity of nanosilver.
Literature extensively reports antibacterial, antiviral and antifungal activities of metallic nanoparticles; however, researches aiming at antileishmanial activity of these nanomaterials are still limited. Mohebali et al. (2009) demonstrated the efficacy of silver nanoparticles on L. major, with these being shown to be promising for treatment of the cutaneous leishmaniasis. The same effect was observed by Torabi et al. (2011) with gold nanoparticles on L. major. Allahverdiyev et al. (2011) evaluated the antileishmania effect of silver nanoparticles on L. tropica based on investigation of their action on various cellular parameters of the promastigote and amastigote forms of parasite when in the absence and presence of UV light. Hence, the importance of evaluating the activity of AuNPs-TA and AgNPs-TA on L. amazonensis, whose synthetic routes employed a natural origin compound abundant in the Brazilian northeast (Mohebali et al. 2009, Toraby et al. 2011).

In this work, we showed that the synergism between tannic acid and silver nanoparticles, into the hybrid nanomaterial (AgNPs-TA), potentiated the tannin activity by about 40 times. This synergism was also responsible for attenuating the cytotoxicity of silver (Table I). These results open a possibility of studing new materials containing polyphenolic derivatives with promising application in the treatment of neglected diseases. Moreover, our

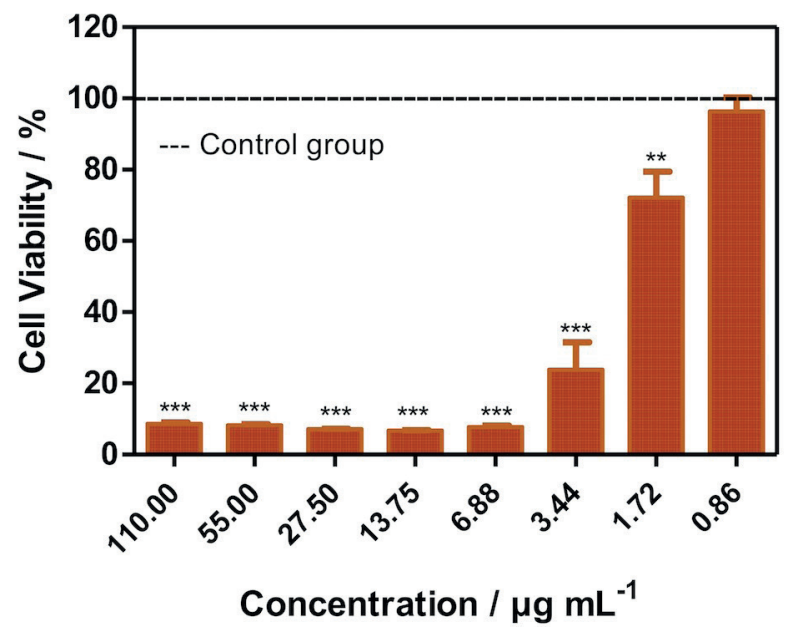

Figure 6 - Effect of AgNPs-TA on viability of murine peritoneal macrophages. Value expressed as mean \pm standard error, $* * * p<0.0001$ 
TABLE I

Antileishmanial and cytotoxic effects of nanoparticles and their precursors.

\begin{tabular}{ccc}
\hline & $\begin{array}{c}\text { Promastigotes } \\
\mathrm{IC}_{50}\left(\mu \mathrm{g} \cdot \mathrm{mL}^{-1}\right) 48 \mathrm{~h}\end{array}$ & $\begin{array}{c}\text { Macrophages } \\
\mathrm{CC}_{50}\left(\mu \mathrm{g} \cdot \mathrm{mL}^{-1}\right) 48 \mathrm{~h}\end{array}$ \\
\hline $\mathrm{TA}$ & $221.81 \pm 97.08$ & $\mathrm{ND}$ \\
AgNPs-TA & $5.85 \pm 1.76$ & $2.38 \pm 1.44$ \\
AuNPs-TA & $\mathrm{ND}$ & $\mathrm{NR}$ \\
Citrate & $\mathrm{ND}$ & $\mathrm{ND}$ \\
AgNPs & $6.96 \pm 3.49$ & $17.10 \pm 4.32$ \\
AuNPs & $\mathrm{ND}$ & $\mathrm{NR}$ \\
\hline
\end{tabular}

findings suggest that these hybrid nanomaterials can be used as anionic polyelectrolytes in fabrication of thin films, aiming to (bio)sensors development for biomedical application.

\section{CONCLUSIONS}

We evaluated the inhibitory effects of TA-coated silver and gold nanoparticles against Leishmania amazonensis promastigotes. Tannic coating of silver and gold nanoparticles resulted in two different supramolecular arrangment types and suffered red-shifts on their SPR bands. No antileishmanial activity was verified for gold nanoparticles under studied conditions. On the other hand, silver nanoparticles immobilized on tannic acid have potential application as an antileishmanial therapeutic. A similar behavior was observed for AuNPs-Cit and AgNPs-Cit, however, tannin incorporation is necessary to increase nanoparticles stability and improve their dispersion. Furthermore, the use of natural compounds contributes to the development of clean, nontoxic, biocompatible and environmentally benign approaches to synthesize noble metal nanoparticles.

\section{ACKNOWLEDGMENTS}

The financial support from the Conselho Nacional de Desenvolvimento Científico e Tecnológico (CNPq) (process number 310678/2014-5) and
Coordenação de Aperfeiçoamento de Pessoal de Nível Superior (CAPES) - nBioNet is gratefully acknowledged.

\section{REFERENCES}

ABED M, HERRMANN T, ALZOUBI K, PAKLADOK T AND LANG F. 2013. Tannic acid induced suicidal erythrocyte death. Cell Physiol Biochem 32: 1106-1116.

AGNIHOTRI S, MUKHERJI S AND MUKHERJI S. 2014. Size-controlled silver nanoparticles synthesized over the range 5-100 $\mathrm{nm}$ using the same protocol and their antibacterial efficacy. RSC Adv 4: 3974-3983.

AKBARI M, ORYAN A AND HATAM G. 2017. Application of nanotechnology on treatment of leishmaniasis: A review. Acta Trop 172: 86-90.

ALLAHVERDIYEV AM, ABAMOR ES, BAGIROVA M, USTUNDAG CB, KAYA C, KAYA F AND RAFAILOVICH M. 2011. Antileishmanial effect of silver nanoparticles and their enhanced antiparasitic activity under ultraviolet light. Int J Nanomed 6: 2705-2714.

ASHARANI PV, WU YL, GONG Z AND VALIYAVEETTIL S. 2008. Toxicity of silver nanoparticles in zebrafish models. Nanotechnology 19: 1.

BHOSALE RR, KULKARNI AS, GILDA SS, ALOORKAR NH, OSMANI RAAND HARKARE BR. 2014. Innovative Eco-friendly Approaches for Green Synthesis of Silver Nanoparticles. Int J Pharm Sci Nanotech 7: 2328-2337.

BLANCO VR AND NASCIMENTO-JÚNIOR NM. 2017. Leishmaniose: Aspectos gerais relacionados com a doença, o ciclo do parasita, fármacos disponíveis, novos protótipos e vacinas. Rev Virtual Quim 9: 861-876.

BRUNEL F, VÉRON L, LADAVIÈRE C, DAVID L, DOMARD A AND DELAIR T. 2009. Synthesis and structural characterization of chitosan nanogels. Langmuir 25: 8935-8943.

BULUT E AND OZACAR M. 2009. Rapid, Facile Synthesis of Silver Nanostructure Using Hydrolyzable Tannin. Ind Eng Chem Res 48: 5686-5690.

CAÑAMARES MV, GARCIA-RAMOS JV, GÓMEZVARGA JD, DOMINGO C AND SANCHEZ-CORTES S. 2005. Comparative study of the morphology, aggregation, adherence to glass, and surface-enhanced Raman scattering activity of silver nanoparticles prepared by chemical reduction of $\mathrm{Ag}^{+}$using citrate and hydroxylamine. Langmuir 21: 8546-8553.

CARNEIRO SMP, CARVALHO FAA, SANTANA LCLR, SOUSA APL, MOITA-NETO JM AND CHAVES MH. 2012. The cytotoxic and antileishmanial activity of extracts and fractions of leaves and fruits of Azadirachta indica. Biol Res 45: 111-116.

CATALANO PN, PEZZONI M, COSTA C, SOLER-ILLIA GJAA, BELLINO MG AND DESIMONE MF. 2016. 
Optically transparente silver-loaded mesoporous thin film coating with long-lasting antibacterial activity. Micropor Mesopor Mat 236: 158-166.

CHEN M, YANG Z, WU H, PAN X, XIE X AND WU C. 2011. Antimicrobial activity and the mechanism of silver nanoparticle thermosensitive gel. Int J Nanomed 6: 28732877.

CHUNG SY AND REED S. 2012. Removing peanut allergens by tannic acid. Food Chem 134: 1468-1473.

DUBEY SP, LAHTINEN M AND SILLANPAA M. 2010. Tansy fruit mediated greener synthesis of silver and gold nanoparticles. Process Biochem 45: 1065-1071.

DURÁN N, MARCATO PD, CONTI RD, ALVES OL, COSTA FTM AND BROCCHI M. 2010. Potential use of silver nanoparticles on pathogenic bacteria, their toxicity and possible mechanisms of action. J Braz Chem Soc 21: 949-959.

EL-BASHIR SM, BARAKAT FM AND ALSALHI MS. 2013. Metal-enhanced fluorescence of mixed coumarin dyes by silver and gold nanoparticles: Towards plasmonic thinfilm luminescent solar concentrator. J Lumin 143: 43-49.

ESPINASSE B, HOTZE EM AND WIESNER MR. 2007. Transport and retention of colloidal aggregates of $\mathrm{C}_{60}$ in porous media: effects of organic macromolecules, ionic composition, and preparation method. Environ Sci Technol 41: 7396-7402.

HATIPOGLU MK, KELESTEMUR S, ALTUNBEK M AND CULHA M. 2015. Source of cytotoxicity in a colloidal silver nanoparticle suspension. Nanotechnology 26: 1-13.

HERRERA-BECERRA R, RIUS JL AND ZORRILLA C. 2010. Tannin biosynthesis of iron oxide nanoparticles. Appl Phys A-Mater 100: 453-459.

HUANG X, WU H, LIAO X AND SHI B. 2010. One-step, size-controlled synthesis of gold nanoparticles at room temperature using plant tannin. Green Chem 12: 395-399.

IRAVANI S. 2011. Green synthesis of metal nanoparticles using plants. Green Chem 13: 2638-2650.

IRAVANI S AND ZOLFAGHARI B. 2013. Green Synthesis of Silver Nanoparticles Using Pinus eldarica Bark Extract. BioMed Res Int 2013: 639725.

JEBALI A AND KAZEMI B. 2013. Nano-based antileishmanial agents: A toxicological study on nanoparticles for future treatment of cutaneous leishmaniasis. Toxicol In Vitro 27: 1896-1904.

KEVRIC I, CAPPEL MA AND KEELING JH. 2015. New World and Old World Leishmania Infections: A Practical Review. Dermatol Clin 33: 579-593.

KUMARI MM, AROMAL SA AND PHILIP D. 2013. Synthesis of monodispersed palladium nanoparticles using tannic acid and its optical non-linearity. Spectrochimica Acta A 103: 130-133.

LAZARUS GG AND SINGH M. 2016. In vitro cytotoxicity activity and transfection efficiency of polyethyleneimine functionalized gold nanoparticles. Colloid Surface B 145 : 906-911.

LIU F, KOZLOVSKAYA V, ZAVGORODNYA O, MARTINEZ-LOPES C, CATLEDGEBC S AND KHARLAMPIEVA E. 2014. Encapsulation of anticancer drug by hydrogen-bonded multilayers of tannic acid. Soft Matter 10: 9237-9247.

LOPES GK, SCHULMAN HM AND HERMES-LIMA M. 1999. Polyphenol tannic acid inhibits hydroxyl radical formation from Fenton reaction by complexing ferrous ions. Biochim Biophys Acta 1472: 142-1452.

MAHMOUD MA, CHAMANZAR M, ADIBI A AND ELSAYED MA. 2012. Effect of the dielectric constant of the surrounding medium and the substrate on the surface plasmon resonance spectrum and sensitivity factors of highly symmetric systems: silver nanocubes. J Am Chem Soc 134: 6434-6442.

MAQUIAVELI CC, ROCHETTI AL, FUKUMASU H, VIEIRA PC AND SILVA ER. 2017. Antileishmanil activity of verbascoside: Selective arginase inhibition of intracellular amastigotes of Leishmania (Leishmania) amazonensis with resistance induced by LPS plus IFN- $\gamma$. Biochem Pharmacol 127: 28-33.

MARTINSSON E, OTTE MA, SHAHJAMALI MM, SEPULVEDA B AND AILI D. 2014. Substract effect on the Reffractive Index sensity of silver nanoparticles. J Phys Chem C 118: 24680-24687.

MEDICI S, PEANA M, NURCHI VM, LACHOWICZ JI, CRISPONI G AND ZORODDU MA. 2015. Noble metals in medicine: latest advances. Coordin Chem Rev 284: 329350.

MELO JR MA, SANTOS LSS, GONÇALVES MC AND NOGUEIRA AF. 2012. Preparação de nanopartículas de prata e ouro: um método simples para a introdução da nanociência em laboratório de ensino. Quim Nova 35: 1872-1878.

MICHEN B, GEERS C, VANHECKE D, ENDES C, ROTHEN-RUTISHAUSER B, BALOG S AND PETRIFINK A. 2015. Avoiding drying-artifacts in transmission electron microscopy: characterizing the size and colloidal state of nanoparticles. Sci Rep-UK 5: 1-7.

MISHIRA G, SINGH D, YADAWA PK, VERMA SK AND YADAV RR. 2013. Study of Copper/Palladium Nanoclusters Using Acoustic Particle Sizer. Platinum Met Rev 57: 186-191.

MOHEBALI M, REZAYAT MM, GILANI K, SARKAR S, AKHOUNDI B, ESMAEILI J, SATVAT T, ELIKAEE S, CHAREHDAR S AND HOOSHYAR H. 2009. Nanosilver in the treatment of localized cutaneous leishmaniasis caused by Leishmania major (MRHO/-IR/75/ER): an in vitro and in vivo study. J Pharm Sci 17: 285-289.

NO JH. 2016. Visceral leishmaniasis: Revisiting current treatments and approaches for future discoveries. Acta Tropica 155: 113-123.

ORYAN A AND AKBARI M. 2016. Worldwide risk factor in leishmaniasis. Asian Pac J Trop Med 9: 925-932. 
OSTOLSKA I AND WISNIEWSKA M. 2014. Application of the zeta potential measurements to explanation of colloidal $\mathrm{Cr}_{2} \mathrm{O}_{3}$ stability mechanism in the presence of the ionic polyamino acids. Colloid Polym Sci 292: 2453-2464.

PAINO IMM, MARANGONI VS, DE OLIVEIRA RCS, ANTUNES LMG AND ZUCOLOTTO V. 2012. Cyto and genotoxicity of gold nanoparticles in human hepatocellular carcinoma and peripheral blood mononuclear cells. Toxicol Lett 215: 119-125.

PARAMASIVAM G, KAYAMBU N, RABEL AM, SUNDRAMOORTHY AK AND SUNDARAMURTHY A. 2017. Anisotropic noble metal nanoparticles: Synthesis, surface functionalization and applications in biosensing, bioimaging, drug delivery and theranostics. Acta Biomater 49: 45-65.

PEREIRA FC, ZANONI MVB, MORETTO LM AND UGO P. 2007. Características ópticas e morfológicas de nanoestruturas de ouro. Quim Nova 30: 1550-1554.

PERNI S, PICCIRILLO C, PRATTEN J, PROKOPOVICH P, CHRZANOWSKI W, PARKIN IP AND WILSON M. 2009. The antimicrobial properties of lightactivated polymers containing methylene blue and gold nanoparticles. Biomaterials 30: 89-93.

QASIM M, LIM D, PARK H AND NA D. 2014. Nanotechnology for diagnosis and treatment of infectious diseases. J Nanosci Nanotechno 14: 7374-7387.

SANTOS AFM, MACEDO LJA, CHAVES MH, CASTAÑEDA ME, MERKOÇI A, LIMA FCA AND CANTANHÊDE W. 2016. Hybrid Self-Assembled Materials Constituted by Ferromagnetic Nanoparticles and Tannic Acid: A Theoretical and Experimental Investigation. J Braz Chem Soc 27: 727-734.

SHARIFI N, DABIRIAN A, DANAEI D AND TAGHAVINIA N. 2015. Aggregates of plasmonic nanoparticles for broadband light trapping in dye-sensitized solar cells. J Opt-UK 18: 1-7.

SHARMA VK, YNGARD RA AND LIN Y. 2009. Silver nanoparticles: green synthesis and their antimicrobial activities. Adv Colloid Interfac 145: 83-96.

SHENY DS, MATHEW J AND PHILIP D. 2012. Synthesis characterization and catalytic action of hexagonal gold nanoparticles using essential oils extracted from Anacardium occidentale. Spectrochim Acta A 97: 306-310.

SHUTAVA T, PROUTY M, KOMMIREDDY D AND LVOV Y. 2005. pH Responsive decomposable layerby-layer nanofilms and capsules on the basis of tannic acid. Macromolecules 38: 2850-2858.

SILVA ATB, COELHO AG, LOPES LCS, MARTINS MVA, CRESPILHO FN, MERKOÇI A AND SILVA WC. 2013. Nano-assembled supramolecular films from chitosan-stabilized gold nanoparticles and Cobalt(II) phthalocyanine. J Braz Chem Soc 24: 1237-1245.

SONG D AND JING D. 2012. Insight into the localized surface plasmon resonance property of core-satellite nanostructures: Theoretical prediction and experimental validation. J Colloid Interf Sci 505: 373-382.

TIKOO K, SANE MS AND GUPTA C. 2011. Tannic acid ameliorates doxorubicin-induced cardiotoxicity and potentiates its anti-cancer activity: potential role of tannins in cancer chemotherapy. Toxicol Appl Pharm 251: 191-200.

TORABI N, MOHEBALI M, SHAHVERDI AR, REZAYAT SM, EDRISSIAN GH, ESMAEILI J AND CHAREHDAR S. 2011. Nanogold for the treatment of zoonotic cutaneous leishmaniasis caused by Leishmania major (MRHO/IR/75/ ER): an animal trial with methanol extract of Eucalyptus camaldulensis. J Pharm Sci 1: 113-116.

VIEITES M, SMIRCICH P, GUGGERI L, MARCHÁN E, GÓMEZ-BARRIO A, NAVARRO M, GARAT B AND GAMBINO D. 2009. Synthesis and characterization of a pyridine-2-thiol N-oxide gold(I) complex with potent antiproliferative effect against Trypanosoma cruzi and Leishmania sp. insight into its mechanism of action. J Inorg Biochem 103: 1300-1306.

YANG KH, LIU YC, YU CC AND CHEN BC. 2011. Fabrication of chitosan/silver nanocomposites based on electrochemical methods for removing formaldehyde in air. Mater Chem Phys 126: 993-997.

YI Z, LI X, XU X, LUO B, LUO J, WU W, YI Y AND TANG Y. 2011. Green, effective chemical route for the synthesis of silver nanoplates in tannic acid aqueous solution. Colloids Surface A 392: 131-136.

ZHANG X, LIU M, ZHANG X, DENG F, ZHOU C, HUI J, LIU W AND WEI Y. 2015. Interaction of tannic acid with carbon nanotubes: enhancement of dispersibility and biocompatibility. Toxicol Res UK 4: 160-168.

\section{SUPPLEMENTARY MATERIAL}

Figure S1 - UV-Vis electronic spectra for aqueous solutions of $\mathrm{HAuCl}_{4} 0.7 \mathrm{mmol} \cdot \mathrm{L}^{-1}, \mathrm{AgNO}_{3} 5.89 \mathrm{mmol} \cdot \mathrm{L}^{-1}, \mathrm{TA} 0.2 \mathrm{mmol} \cdot \mathrm{L}^{-1}$ and citrate $20 \mathrm{mmol} \cdot \mathrm{L}^{-1}$.

Figure S2 - UV-Vis electronic spectra for colloidal dispersions of bare nanoparticles. Inset: Tyndall effect observed for each dispersion.

Figure S3 - Effect of (a) AgNPs-TA and (b) TA against $L$. amazonensis promastigotes at different concentrations. Value expressed as mean \pm standard error, ${ }^{* * *} p<0.0001$.

Figure S4 - Inhibitory effect of AgNPs on L. amazonensis promastigotes. Value expressed as mean \pm standard error, $* * * p$ $<0.0001$.

Figure S5 - Optical microscopy views of parasite cultures (a) in control group (abscence of nanoparticles), (b) exposed to AuNPs, and (c) exposed to AgNPs. Quick panoptic staining and 100x magnification.

Figure S6 - Effect of AgNPs on viability of murine peritoneal macrophages. Value expressed as mean \pm standard error, $* * * p$ $<0.0001$. 